\title{
First Report on Host Range of Myrothecium roridum Infecting Arabica Coffee (Coffea arabica L.) in India
}

\author{
Madhu S. Giri*, A. P. Ranjini, Santoshreddy Machenahalli, \\ M. Sudha and S. Daivasikamani
}

Division of Plant Pathology, Central Coffee Research Institute, Coffee Research Station - 577 117, Chikkamagaluru District, Karnataka, India

*Corresponding author

\section{A B S T R A C T}

\section{Keywords}

Coffee, Cross inoculation, Leaf spot, Myrothecium roridum, Weed

Article Info

Accepted:

04 September 2020 Available Online: 10 October 2020
Coffee is one of the most popular non-alcoholic beverages consumed all over the world. The coffee industry offers lively hood for millions of people directly and indirectly among the coffee growing countries. The coffee crop is known to be affected by many diseases at different seasons. Earlier, the pathogen Myrothecium was known to cause stem necrosis and leaf spot disease on coffee seedlings in the nursery. In the recent years, there was a gradual increase in the incidence of leaf spot and fruit rot of Arabica coffee caused by Myrothecium in the field condition during rainy season. During the visit to coffee plantations in Chikkamagaluru and Hassan districts, the plants and weeds growing in and around the coffee plantation were observed for the presence of leaf spot with typical symptoms caused by Myrothecium. A total of eleven different plant species viz., Colocasia sp., Alternanthera bettzickiana, Remusatia vivipara, Phlebodium aureum, Alternanthera brasiliana, Polypodium triseriale, Urtica sp., Artocarpus heterophyllus, Tarenna asiatica, Impatiens dasysperma and Hibiscus rosa-sinensis with typical symptoms of Myrothecium were identified. Based on the morphological character the fungal cultures were identified as Myrothecium roridum. The development of typical symptoms of Myrothecium on the Arabica coffee leaves cross-inoculated with pure fungal culture indicated the cross infecting ability of the fungus isolated from different host plants. As per our knowledge this is the first report indicating the cross infecting ability of the Myrothecium roridum cultures on Arabica coffee leaves isolated from different host plants, majority of them were weed plants commonly grown in and around coffee plantation.

\section{Introduction}

Coffee is one of the most important economic plantation crop of tropical and sub-tropical climate of the world. Coffee in India is mainly cultivated in the hilly tracts of Western and Eastern Ghats. This perennial plantation crop cultivated under agro-forestry ecosystem provides livelihood to millions of people involved in the coffee production chain and it is one of the major sources of foreign exchange earnings for most of the coffee producing countries. 
The two commercially cultivated species of Coffea viz., Coffea Arabica L. (Arabica coffee) and $C$. canephora Pierre ex A. Froehner (Robusta coffee) are affected by many fungal diseases. Some of the fungal diseases are restricted to the early stage of nursery and usually causes seedling loss which inturn hamper the establishment of healthy plantation.

Among the nursery diseases, the leaf spot and stem necrosis caused by Myrothecium roridum Tode ex Fr. which occurs during rainy season under favourable weather condition causes huge mortality of seedlings. Earlier, this disease was considered as minor and restricted to nursery (Daivasikamani et al., 2016). But, in the recent years it was noticed that the occurrence of leaf spot and stem necrosis was very severe in the nursery which resulted in huge mortality of coffee seedlings. Similarly, it was also noticed that there is a drastic increase in the incidence of leaf spot and berry rot caused by Myrothecium roridum in field conditions during rainy season in the recent past indicating the changes in the dynamics of disease development and spread.

Myrothecium roridum is a common soil inhabiting fungus with a relatively wide host range that includes such agronomic crops as cotton, tomato, cocoa, coffee, potato, soybean and cucurbits as well as various ornamental plants (Ponnappa, 1970; Chase, 1983; Bruton, 1996; Kim et. al., 2003; Kyung et al., 2014) and causes leaf spot and stem necrosis. In India, Nagaraj and George (1958) reported the Myrothecium disease on coffee seedlings as "Target Leaf Spot". Further, he reported that the same pathogen could infect the leaves and berries of coffee plants in field condition. Later, Nirmala Kannan and Muthappa (1982) reported the Myrothecium disease as "Tip blight of coffee".
In the recent past, increased incidence of Myrothecium leaf spot and berry rot was observed on field grown Arabica plants in many plantations of Chikkamagaluru, Hassan and Kodagu districts of Karnataka during rainy season. Myrothecium roridum infecting other agricultural and horticultural crop is known to have a wide host range. In view of this, a study was initiated to investigate the collateral or alternate hosts and efforts has been made to identify the weed plants with typical symptoms of Myrothecium infection during the visit to coffee plantation under rainy season which acts as additional source of inoculums for disease spread. The result of the study will enable to develop suitable weed management practices and to contain the disease during rainy season.

\section{Materials and Methods}

\section{Collection of samples}

The infected leaves showing typical leaf spot symptoms of Myrothecium roridum were collected from the plantation of various coffee zones of Chikkamagaluru and Hassan districts (Table 1). The infected leaf samples were brought to the Plant Pathology Laboratory, Central Coffee Research Institute (CCRI) and were examined under stereo-microscope (Nikon SMZ - 800) for preliminary identification of the pathogen.

\section{Isolation of pathogen}

From the infected leaves, the pathogen was isolated by transferring sporodochia directly from the infected host tissue to the Petridishes (90 $\mathrm{mm}$ diameter) containing Potato Dextrose Agar (PDA) and incubated at $25 \pm 1^{\circ} \mathrm{C}$. The colonies of the fungus was further purified by single spore culture technique and maintained on PDA medium at $25 \pm 1^{\circ} \mathrm{C}$. 
Proving pathogenicity on coffee / Cross inoculation on coffee

Twenty days old active cultures of the pathogen with sporodochia cultured on PDA medium were used for inoculation. Culture discs $(9 \mathrm{~mm}$ diameter) of Myrothecium isolated from different host plants were prepared by using cork borer. Such culture discs were used for inoculation. Leaves selected for inoculation were surface disinfected with $70 \%$ ethanol. Leaves of Arabica coffee plants in the field were inoculated at multiple sites with culture discs of Myrothecium on lower surface of the leaves. Further, inoculated discs were covered with a thin layer of absorbent cotton to avoid desiccation of culture discs.

The inoculated leaves were then kept moist for 10 days by covering the branches with polypropylene bags to create high humidity. Similarly, un-inoculated control was maintained by placing PDA discs on the lower side of the leaves. Observations on the development of disease symptoms and reaction of the host to pathogen were recorded every day.

\section{Results and Discussion}

The stereo-microscopic observation of leaves of different host plants viz., Colocasia sp., Alternanthera bettzickiana, Remusatia vivipara, Phlebodium aureum, Alternanthera brasiliana, Polypodium triseriale, Urtica sp., Artocarpus heterophyllus, Tarenna asiatica, Impatiens dasysperma and Hibiscus rosasinensis collected from coffee plantation of different locations suspected to be infected with Myrothecium showed the presence of black coloured sporodochia (Figure M. r. 1 to M. r. 11). The details of host plant and locations from where they collected are presented in table 1 .

Table.1 Myrothecium roridum infected leaf samples collected from different host plants and their locations

\begin{tabular}{|l|l|l|l|l|}
\hline \multicolumn{1}{|c|}{ Isolate } & \multicolumn{1}{|c|}{ Host plant } & \multicolumn{1}{|c|}{ Family } & \multicolumn{1}{|c|}{ Location } & \multicolumn{1}{|c|}{ District } \\
\hline M. r. 1 & Colocasia sp. & Araceae & Hanthuru & Chikkamagaluru \\
\hline M. r. 2 & $\begin{array}{l}\text { Alternanthera } \\
\text { bettzickiana }\end{array}$ & Amaranthaceae & CCRI farm & Chikkamagaluru \\
\hline M. r. 3 & Remusatia vivipara & Araceae & CCRI farm & Chikkamagaluru \\
\hline M. r. 4 & Phlebodium aureum & Polypodiaceae & CCRI farm & Chikkamagaluru \\
\hline M. r. 5 & Alternanthera brasiliana & Amaranthaceae & TEC, Mudigere & Chikkamagaluru \\
\hline M. r. 6 & Polypodium triseriale & Polypodiaceae & TEC, Mudigere & Chikkamagaluru \\
\hline M. r. 7 & Urtica sp. & Urticaceae & TEC, Mudigere & Chikkamagaluru \\
\hline M. r. 8 & $\begin{array}{l}\text { Artocarpus } \\
\text { heterophyllus }\end{array}$ & Moraceae & $\begin{array}{l}\text { TEC, } \\
\text { Sakaleshpura }\end{array}$ & Hassan \\
\hline M. r. 9 & Tarenna asiatica & Rubiaceae & Taluvane & Chikkamagaluru \\
\hline M. r. 10 & Impatiens dasysperma & Balsaminaceae & Hiregadde & Chikkamagaluru \\
\hline M. r. 11 & Hibiscus rosa-sinensis & Malvaceae & Ossuru & Hassan \\
\hline
\end{tabular}


Fig.1 Pure cultures of Myrothecium roridum and their respective host plants

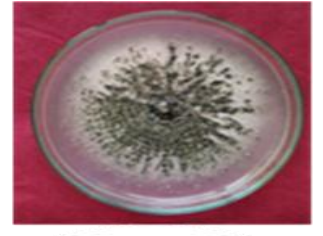

M. r. 1

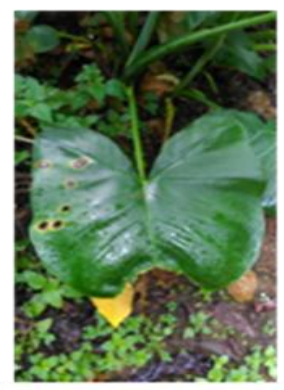

Colocasia sp.

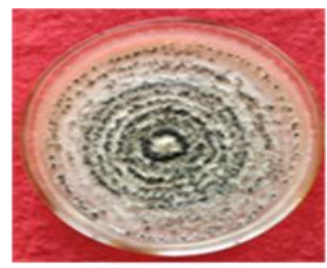

M. r. 4

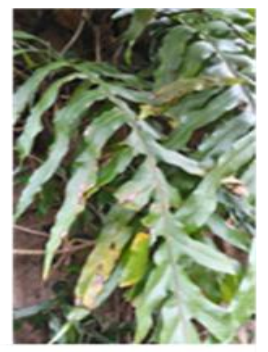

Phlebodium aureum

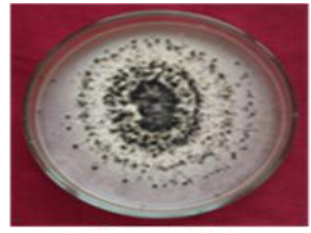

M. r. 2

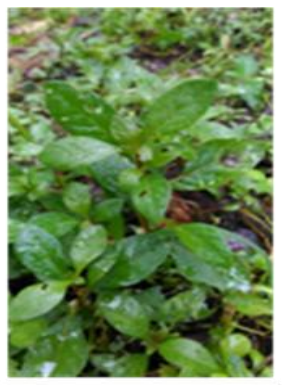

Alternantherve bettrickiana

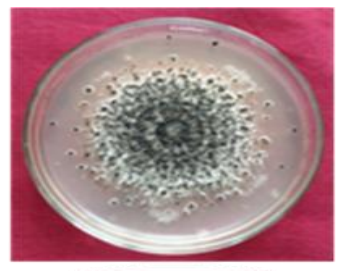

M. r. 5

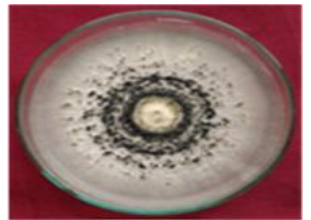

M. r. 3

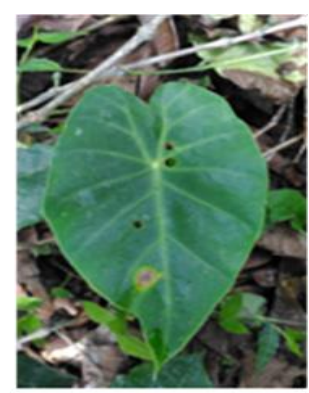

Remusatia vivipary

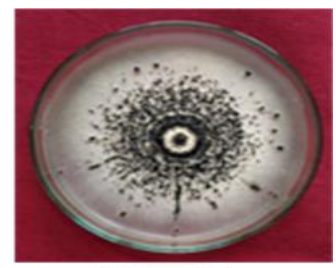

M. r. 6

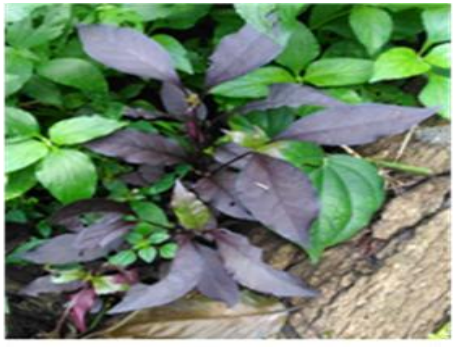

Alternanthenc brusiliana

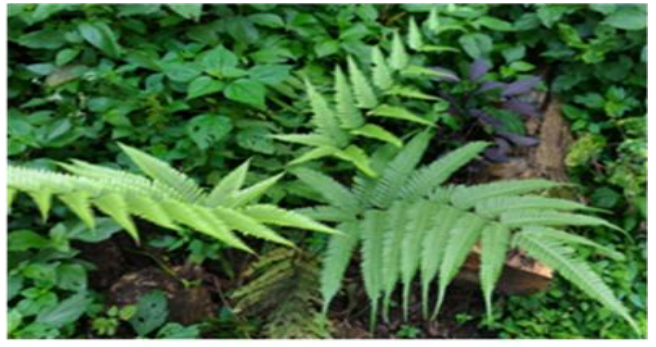

Polypodium triseriale 


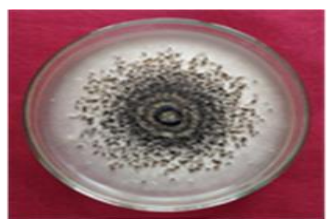

M r. 7

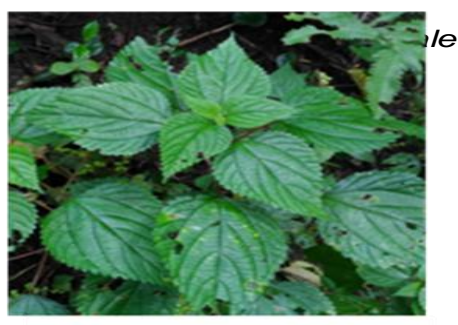

Urtica sp.

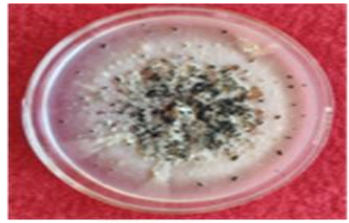

M r. 10

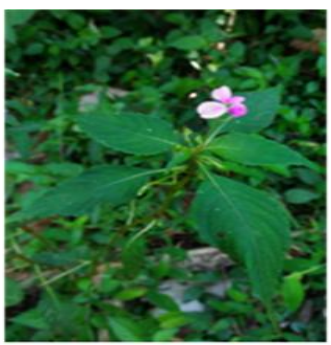

Impatiens dasysperma

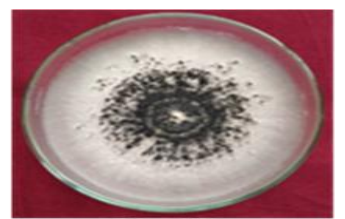

M. r. 8

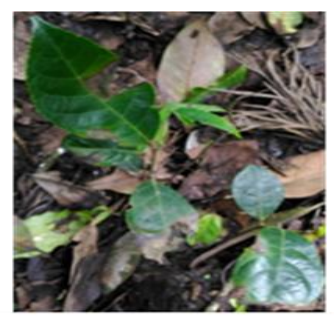

Artocarpus heterophyllus

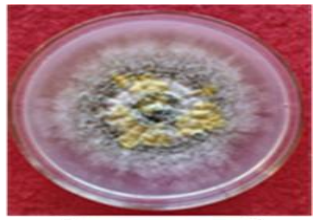

M r. 11

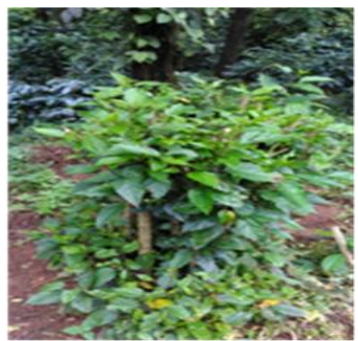

Hibiscus

mosa-sinensis

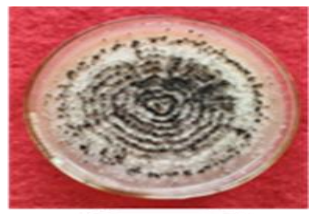

MI r. 9

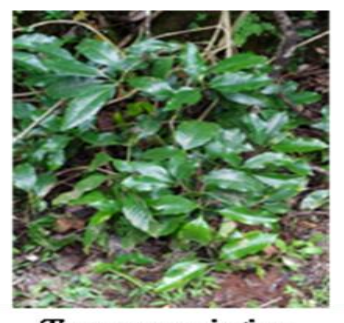

Tanenna asiatica

\section{Isolation of pathogen}

Fungal cultures were obtained from lesions and cultivated on PDA medium and incubated at $25 \pm 1^{\circ} \mathrm{C}$ in the dark. In the culture, the fungal colonies reached $90 \mathrm{~mm}$ diameter on PDA 20 to 22 days after incubation. Initially colonies of the isolates were white, floccose, wrinkled, somewhat raised at the centre. Sporulation occurred throughout the colony in concentric greenish black zones. These zones consisted of cluster of conidiophores forming sporodochia. Conidia were rod shaped. The characteristics of the fungus were consistent with those reported for $M$. roridum by earlier investigators (Seebold et al., 2005; Mangandi et al., 2007; Han et al., 2014; Ben et al., 2015; Ranjini and Rajanaika, 2018).

\section{Cross inoculation of cultures on Arabica coffee}

In cross inoculation study, all healthy Arabica coffee leaves showed typical symptoms 7 to 10 days after inoculation, while un-inoculated control leaves remained symptomless. The typical symtoms were dark brown, circular or sub-circular lesions on leaf surface. Lesions 
expanded gradually. Later, the infected leaves turned yellow and abscised. At later stage, black sporodochia with white mycelial tufts were produced. The same fungus was reisolated from inoculated plants, but not from the un-inoculated controls.

Myrothecium roridum has an extensive host range, covering 294 species host plant (http://nt.ars-agrin.gov/fungal databases) and 23 genera of foliage plants which were considered as potential hosts of $M$. roridum (Chase, 1987). Quezado-Duval et al., (2010) also found out some unfamiliar hosts of Myrothecium fungi in Brazil. In their study they have isolated $M$. roridum and $M$. verrucaria from three vegetable plants (Sweet pepper, tomato and cucumber), four ornamental species (Spathiphyllum wallisi, Solidogo Canadensis, Anthurium andraeanum and Diffenbachia amoena) and a weed belonging to solanaceae family (Nicandra physaloides) and confirmed pathogenicity.

Similarly, Ranjini et al., (2019), artificially inoculated the pathogen $M$. roridum to the leaves of black pepper vines that is existing on coffee and confirmed its ability to infect black pepper vines.

The present study revealed that Myrothecium roridum isolated from different host plants growing in and around coffee plantation can infect leaves of Arabica coffee plants and produce necrotic leaf spots. Even though there are numerous reports of $M$. roridum as a pathogen of coffee seedlings, to our knowledge, this is the first report in India and world indicating the cross infecting ability of M. roridum causing leaf spots on Arabica coffee which were isolated from different host plants growing in and around coffee plantation.

This study also provides a hint for the increased incidence of necrotic leaf spot and berry rot caused by Myrothecium in the field condition during monsoon season in the recent years. As the pathogen has got fairly wide host range, timely action is needed to restrict its spread on coffee through maintenance of sanitation in the plantation by keeping the plantation free from weeds.

\section{Acknowledgements}

The authors wish to thank the Director of Research, Central Coffee Research Institute (CCRI), Balehonnur for providing the required facilities to carry out the studies. The authors are also grateful to scientists of All India Co-ordinated Research Project on Weed Management (Gandhi Krishi Vignana Kendra), Bengaluru for their support in identification of weed plants.

\section{References}

Ben, H. Y., Yan-Jie Zhao, Y. J., A-Li Chai, A. L., Shi, Y. X., Xie, X. W. and Li, B. J. 2015. First Report of Myrothecium roridum Causing Leaf Spot on Anthurium andraeanum in China. Journal of Phytopathology. 163: 144-147.

Bruton, B. D. 1996. "Crater Rot," In: T. A. Zitter, D. L. Hop-kins and C. E. Thomas, Eds., Compendium of Cucurbit Diseases, The American Phytopathological Society, St. Paul. pp. 49-50.

Chase, A. R. 1983. Influence of Host Plant and Isolate Source on Myrothecium Leaf Spot of Foliage Plants. Plant Disease. 67(6): 668-671.

Chase, A. R. 1987. Compendium of Ornamental Foliage Plant Diseases. St Paul, MN, USA, APS Press.

Daivasikamani, S., Ranjini, A. P. and Raghuramulu, Y. 2016. Diseases of coffee and their management. In: Plant Pathogens and their management. 
(Ed). Trivedi PC, Avaishkar Publishers, Distributors, Jaipur, Rajasthan, India. pp. 19-50.

Han, K. S., Choi, S. K., Kim, H. H., Lee, S. C., Park, J. H., Cho, M. R. and Park, M. J. 2014. First Report of Myrothecium roridum Causing Leaf and Stem Rot Disease on Peperomia quadrangularis in Korea. Mycobiology. 42(2): 203-205.

Kim, D. K., Bae, D. W., Lee, S. C., Han, K. S. and Kim, H. K. 2003. Detection of Myrothecium Leaf Spot, a New Disease of Watermelon. Plant Pathology Journal. 19(4): 200-202.

Kyung, S. H., Seung, K. C., Hyeong, H. K., Sung, C. L., Jong, H. P., Myoung, R. C. and Mi-Jeong, P. 2014. First Report of Myrothecium roridum causing leaf and stem rot disease on Pepromia quandrangularis in Korea. Mycobiology. 42: 203-205.

Mangandi, J. A., Seijo, T. E. and Peres, N. A. 2007. First report of Myrothecium roridum causing Myrothecium leaf spot on Salvia spp. in the United States. Plant Disease. 91: 772.

Nagraj, T. R. and George, K. V. 1958. Target leaf spot disease of coffee: Occurrence symptoms and etiology. Indian Phytopathology. 11: 153-158.

Nirmala Kannan and Muthappa, B. N. 1982. Tip blight disease of young coffee plants in the nursery. Journal of Coffee
Research. 12: 38-41.

Ponappa, K. M. 1970. On the Pathogenicity of Myrothecium roridum-Eichhornia crassipes Isolate. Hyacinth Control Journal. 8(1): 18-20.

Quezado-Duval, A. M., Henz, G. P., PazLima, M. L., Medeiros, A. R., Miranda, B. E. C., Pfenning, L. H. and Reis, A. 2010. New hosts of Myrothecium spp. in Brazil and a preliminary in vitro assay of fungicides. Brazilian Journal of Microbiology. 41: 246-252.

Ranjini, A. P. and Raja Naika. 2018. Leaf spot and stem necrosis disease of coffee seedlings caused by Myrothecium roridum Tode ex Fr. in India. Journal of Mycopathological Research. 56(1): 5-10.

Ranjini, A. P., Giri, M. S., Daivasikamani, S., Santoshreddy Machenahalli, Sudha, M. and Rajanaika. 2019. First Report on Cross-Infection of Coffee Leaf Spot Pathogen Myrothecium roridum on Black Pepper. International Journal of Current Microbiology and Applied Science. 8(5): 2245-2254.

Seebold, K. W., Langston, D. B., Kemerait, R. C. and Hudgins, J. E. 2005. First report of a leaf spot and stem canker caused by Myrothecium roridum on watermelon in the United States. Plant Disease. 89: 342.

\section{How to cite this article:}

Madhu S. Giri, A. P. Ranjini, Santoshreddy Machenahalli, M. Sudha and Daivasikamani, S. 2020. First Report on Host Range of Myrothecium roridum Infecting Arabica Coffee (Coffea Arabica L.) in India. Int.J.Curr.Microbiol.App.Sci. 9(10): 346-352.

doi: https://doi.org/10.20546/ijcmas.2020.910.043 